\title{
VOCÊ NÃO VAI MORRER SOZINHO: TECNOLOGIA E COMPAIXÃO NA PANDEMIA COVID-19
}

Tercia Soares Sharpe ${ }^{1}$ https://orcid.org/ 0000-0002-9452-271X

Objetivo: Mostrar como o uso da tecnologia na comunicação, tem contribuido para promover o diálogo e a compaixão no atendimento ao paciente, minimizando o isolamento e facilitando a comunicação com entes queridos no fim da vida. Método: Estudo baseado num artigo de opinião. Resultados: Estudo aponta o uso do Face Time como importante ferramenta de comunicação, durante o cuidado aos pacientes internados em Unidade de Tratamento Intensivo e seus familiares. Considerações Finais: Os cuidados de Enfermagem em Unidade de Tratamento Intensivo com o uso de tecnologias de comunicação favorecem a afetividade entre cliente-família-enfermeira, além de estimular a compaixão e a empatia.

Descritores: Enfermagem; Cuidados Paliativos na Terminalidade da Vida; Enfermagem de Cuidados Paliativos na Terminalidade da Vida; Empatia; Infecção por Coronavírus.

\section{YOU WON'T DIE ALONE: TECHNOLOGY AND COMPASSION IN THE COVID-19 PANDEMIC}

Objective: to describe how the use of technology in communication has contributed to promote dialogue and compassion in patient care, minimizing isolation and facilitating communication with loved ones at the end of life. Method: Study based on an opinion article. Results: A study points to the use of Face Time as an important communication tool, during the care of patients admitted to the Intensive Care Unit and their families. Final Considerations: Nursing care in the Intensive Care Unit with the use of communication technologies favors affection between client-family-nurse, in addition to stimulating compassion and empathy.

Descriptors: Nursing; Hospice Care; Hospice and Palliative Nursing Care; Empathy; Coronavirus Infections.

\section{NO MORIRÁS SOLO: TECNOLOGÍA Y COMPASIÓN EN LA PANDEMIA DE COVID-19}

Objetivo: mostrar cómo el uso de la tecnología en la comunicación ha contribuido a promover el diálogo y la compasión en la atención al paciente, minimizando el aislamiento y facilitando la comunicación con los seres queridos al final de la vida. Método: Estudio basado en un artículo de opinión. Resultados: Un estudio señala el uso de Face Time como una herramienta de comunicación importante, durante la atención de pacientes ingresados en la Unidad de Cuidados Intensivos y sus familias. Consideraciones finales: La atención de enfermería en la Unidad de Cuidados Intensivos con el uso de tecnologías de comunicación favorece el afecto entre el cliente-familia-enfermera, además de estimular la compasión y la empatía.

Descriptores: Enfermería; Cuidados Paliativos al Final de la Vida; Enfermería de Cuidados Paliativos al Final de la Vida; Empatía; Infecciones por Coronavirus.

${ }^{1}$ Travel Nurse, em contrato com Yale New Haven Hospital, CT, Estados Unidos.

Autor Correspondente: Tercia Soares Sharpe E-mail: contato@terciasoaressharpe.com

Recebido: 04/5/2020Ａceito: 27/5/2020 


\section{INTRODUÇÃO}

Como enfermeira, tenho trabalhado com o fim da vida nos últimos doze anos, com pacientes que estão em Unidades de Terapia Intensiva (UTI), ajudando-os bem como a seus familiares, a tomarem a melhor decisão quando viver naturalmente deixa de ser uma opção.

O medo de morrer sozinho é quase universal, um fato do qual qualquer pessoa que cuida de um paciente em estado crítico, conhece muito bem. Sempre esforçei-me ao máximo para dar aos pacientes um pouco mais de tempo para os membros da família chegarem e se despedirem. Infelizmente com a pandemia de COVID-19 tem sido muito difícil fazer a promessa habitual de que "faremos tudo o que pudermos para mantê-lo vivo até você chegar aqui"; e em muitos hospitais tem sido impossivel.

A tecnologia ${ }^{1}$ tem auxiliado sobremodo as ações na área da saúde e trazido inúmeros benefícios como novas drogas, vacina, novos equipamentos, testes laboratoriais e principalmente novos protocolos para a ação ante esta pandemia, buscando melhorias para o cuidado.

O objetivo deste relato é mostrar como o uso da tecnologia na comunicação - "telesaúde", tem contribuido para promover o diálogo no atendimento ao paciente, minimizado o isolamento e facilitando a comunicação com entes queridos no fim da vida.

\section{DESENVOLVIMENTO}

Trata-se de um artigo de opinião em que procuro enfatizar parte da minha experiência vivenciada como enfermeira nos Estados Unidos (Travel Nurse, em contrato com Yale New Haven Hospital, CT), durante a pandemia de COVID-19, a partir de março de 2020. Destaco os cuidados de enfermagem que podem ser dados aos pacientes com o uso da tecnologia e a empatia.

Com as visitas totalmente proibidas nos hospitais nesta pandemia, a possibilidade de tocar, beijar, segurar na mão e se despedir do ente querido, deixou de ser uma opção na maioria dos hospitais.

O problema tem vários aspectos. Em muitos casos, os membros da família já passaram algum tempo em contato próximo com o paciente, o que significa que é provável que eles estejam infectados. Além disso, há uma escassez de Equipamentos de Proteção Individual (EPI), e quando os membros da família usam, significa consumir mais recursos escassos. $E$ se os familiares não estiverem infectados, as visitas à família em hospital cheio de pacientes com COVID-19 os colocarão em risco, pois além da exposição, não possuem treinamento adequado no uso de EPI.

A barreira dos pacientes isolados neste hospital que atuo, tem sido minimizada por meio do uso da tecnologia, assim como em diversos outros lugares pelo mundo ${ }^{1,2}$. Todos os quartos de UTI possuem computadores sobre rodas com uma câmera voltada para o paciente. À medida que a "telesaúde" e as reuniões virtuais se tornaram a nova normalidade, a equipe multiprofissional usa smartphone agilizando a comunicação de toda a equipe envolvida no cuidado de cada paciente.

Os profissionais da linha de frente (enfermeiros, médicos e fisioterapeutas respiratórios) usam um aplicativo que possibilita fazer Face Time (FT) com os pacientes. Assim quando o paciente toca a campainha, responde-se por meio do FT e isso tem ajudado a diminuir a ansiedade, solidão e medo que o paciente com COVID-19 enfrenta. É a empatia sendo exercida pela equipe de saúde. O mesmo ocorre com a comunicação entre pacientes e seus familiares, quando necessitam fazer reunião para decisões no rumo do tratamento, mudanças no testamento vital, entre outras condutas.

Neste hospital, quando o paciente consciente decide receber apenas cuidados de conforto, ou quando a família decide por cuidados de conforto no caso de pacientes inconscientes, é permitido que um familiar entre para ficar com este. Muitos são os pacientes que tem familiares que moram distantes ou alguma outra situação que os impede de estarem presentes no desfecho do ciclo da vida.

O objetivo de cuidados paliativos e de conforto é melhorar a qualidade de vida. Infelizmente hoje estas conversas estão acontecendo numa escala nunca vista antes, sobretudo nos Estados Unidos. O público sabe o que está acontecendo porque segue as notícias e a mídia. O que é surpreendente é que pacientes e familiares querem conversar sobre o que eles gostariam se a doença progredisse. Eles se sentem aliviados pela oportunidade de falar sobre o assunto. Alguns têm uma clareza muito grande sobre que tipos de tratamentos querem ser submetidos, e a equipe de saúde está ali para honrar os desejos de cada um. Dessa maneira, cada paciente e cada família usa o direito humano de decidir sobre o fim da vida, e o médico não se sobrecarrega em ter que tomar essa decisão como tem acontecido em outros países nessa pandemia.

É muito difícil dizer certas coisas, quando não pode olhar para a outra pessoa, por isso o hospital dispõe de tablets que os pacientes usam para ver seus familiares e ouvirem o que tem a dizer. Muitas vezes o paciente não tem condições de conversar porque está muito doente ou porque está entubado e sedado. Mesmo assim, a família é encorajada a falar, para o paciente ouvir.

Orienta-se sobre o que deve ser dito, como por exemplo, "obrigado por ser o meu pai", "por favor me perdoe por coisas que eu fiz e the magoei", "eu te amo", e, quando chegar o momento final também dizer "adeus". O benefício de ter condi- 
ções de dizer isso, para alguém que você ama, enquanto ele ainda está aqui, é incalculável. E como enfermeiros precisamos ter a certeza de que esta oportunidade vai ser dada a cada paciente e familiar.

O enfermeiro de UTI além de ter conhecimento, habilidade e experiência, precisa também ser a extensão da família, permanecendo ao lado do paciente, segurando sua mão até a última respiração. É assim que mostramos compaixão, empatia ${ }^{3}$.

Eu sempre pergunto para a família do paciente se há algum ritual que gostariam de manter com relação ao fim da vida e procuro respeitar e honrar a crença de cada um. Ao paciente consciente eu pergunto se ele gostaria que eu fizesse uma oração por ele, e todos sem exceção ficam extremamente gratos. Alguns colegas não se sentem confortáveis e precisamos respeitar a individualidade de cada um.

Os enfermeiros da linha de frente, que assim como eu, lutam contra um inimigo que já matou mais de 200 mil pessoas veem diariamente o sofrimento humano numa escala incomum. Um dia, teremos condições de contar sobre os pacientes que morreram, sem seus familiares e como seguramos sua mão. Um dia vamos contar do medo que sentimos de ir trabalhar e o medo que sentimos ao voltar para casa, para nossa família. Um dia, vamos contar como durante o plantão choramos juntos e oramos juntos. Um dia vamos contar a alegria que sentimos ao aplaudir o paciente que sai da UTI. Um dia... Mas hoje, precisamos ir à guerra contra o COVID-19.

Já fui chamada de rainha do Covid-19, já fui chamada de anjo, já fui banhada por 'aleluias' ao telefone conversando com familiares. Que responsabilidade e que oportunidade!

Obrigada Florence Nightingale por me inspirar a ser luz.
Obrigado meu Deus por me usar como luz.

Gratidão é o que sinto.

\section{Limitações do Estudo}

Deve-se considerar como limitação o fato de apenas ter sido relatado a experiência num único hospital americano, e que se estendida a outros, talvez possibilitasse novos enfoques com outras ferramentas.

\section{Contribuições para a Prática}

O relato oferece a possibilidade de em outras instituições os enfermeiros valorizarem as ações de comunicação de forma simples com o uso da tecnologia em prol dos pacientes.

\section{CONSIDERAÇÕES FINAIS}

Os pacientes sentem solidão intensa e anseiam o convívio com outras pessoas, mas ao mesmo tempo sentem-se excluídos, e isso os angustia. O sofrimento não é apenas físico. O sofrimento é uma mistura de tristeza, angústia, incerteza e desespero'.

O COVID-19 pode até roubar a habilidade de respirar mas não pode roubar a oportunidade de familiares demonstrarem compaixão e empatia até o final do ciclo de uma vida. A tecnologia na comunicação tem sido usada com sucesso em Yale New Haven Hospital.

A despeito da tecnologia, o meu paciente não vai morrer sozinho.

Agradecimentos: Yale New Haven Hospital por ter compaixão de pacientes e familiares nesse momento de isolamento.

\section{REFERÊNCIAS}

1.Almeida JR. O papel da tecnologia no combate ao coronavírus. Saúde Business. Disponível em https:// saudebusiness.com/voce-informa/o-papel-da-tecnologia-no-combate-ao-coronavirus/. Acesso 2020 mai 23.

2.Crispim D, Silva MJP, Cedotti W, Câmara M, Gomes SA. Comunicação difícil e Covid - 19

Disponivel em https://ammg.org.br/wp-content/uploads/comunica\%C3\%A7\%C3\%A3o-COVID-19.pdf.pdf Acesso 2020 mai 23.

3.Sharpe T. Última Palavra Informações importantes sobre direitos humanos no final da vida. Aprenda mais e ajude alguém. São Paulo: Editora Literare Books; 2018. 